University of Nebraska - Lincoln

DigitalCommons@University of Nebraska - Lincoln

$12-2006$

\title{
A New Genus of Moss-Inhabiting Flea Beetles (Coleoptera: Chrysomelidae) from the Dominican Republic
}

\author{
Alexander S. Konstantinov \\ USDA National Museum of Natural History, alex.konstantinov@ars.usda.gov \\ Maria Lourdes Chamorro-Lacayo \\ University of Minnesota, Saint-Paul
}

Follow this and additional works at: https://digitalcommons.unl.edu/systentomologyusda

Part of the Entomology Commons

Konstantinov, Alexander S. and Chamorro-Lacayo, Maria Lourdes, "A New Genus of Moss-Inhabiting Flea Beetles (Coleoptera: Chrysomelidae) from the Dominican Republic" (2006). USDA Systematic Entomology Laboratory. 4.

https://digitalcommons.unl.edu/systentomologyusda/4

This Article is brought to you for free and open access by the Entomology Collections, Miscellaneous at DigitalCommons@University of Nebraska - Lincoln. It has been accepted for inclusion in USDA Systematic Entomology Laboratory by an authorized administrator of DigitalCommons@University of Nebraska - Lincoln. 


\title{
A New Genus of Moss-Inhabiting Flea Beetles (Coleoptera: Chrysomelidae) from the Dominican Republic.
}

\author{
Alexander S. Konstantinov \\ Systematic Entomology Laboratory \\ PSI, Agricultural Research Service, U.S. Department of Agriculture \\ c/o Smithsonian Institution, P.O. Box 37012 \\ National Museum of Natural History, MRC 168 \\ Washington, D.C. 20013-7012, U.S.A. \\ akonstan@sel.barc.usda.gov \\ AND \\ Maria Lourdes Chamorro-Lacayo \\ Department of Entomology \\ University of Minnesota, Saint-Paul, MN 55108, U.S.A. \\ cham0138@umn.edu
}

\begin{abstract}
Kiskeya new genus and two new species (K. baorucae and K. neibae), from the Dominican Republic are described and illustrated. Kiskeya is compared to Monotalla Bechyne, Normaltica Konstantinov, and Clavicornaltica Scherer. Geographic ranges in which Greater Antillean endemics have closest relatives in the Old World are discussed.
\end{abstract}

Moss-inhabiting and moss-feeding in flea beetles are not well understood. Only a few species have been documented as living in mosses, and just one is known to feed on them. The larva of European and Caucasian Mniophila muscorum (Koch) for years was erroneously considered a leaf-miner of various herbaceous plants. However, recent observations of the first instar larva revealed that it is most likely an external feeder on mosses (Cox 1997). In England the adults of Mniophila muscorum are collected throughout the year on several moss species of the genera Rhytidiadelphus (Lindb. ex Limpr.) Warnst. (Hypnaceae) and Eurhynchium Schimp. (Brachythecieae), both of which grow in a variety of habitats and on a variety of substrates (log stumps, fallen trees, tree branches, rocks, walls and chalky slopes; trees include alder, beech and pine) (Cox 1997). Several species of Ivalia Jacoby and one species of Phaelota Jacoby were sifted from unidentified mosses growing on rocks, tree trunks, and soil in southern India (Duckett, Prathapan and Konstantinov in press). The newly described Clavicornaltica dali (Konstantinov and Duckett 2005) was collected from moss in China together with an undescribed species of Benedictus Scherer.

Prior to this study, no flea beetles were known to live in mosses in the New World, although leaf litter inhabitants have been described from the Appalachian Mountains in the United States (Konstantinov and Tishechkin 2004) and have been collected in Central and South America. Extensive leaf beetle collecting in the Dominican Republic yielded a moss-living flea beetle. It was first found in the Sierra de Baoruco in the area called Las Abejas, which has become a classical collecting locality in the western part of the country. The site is a deep ravine situated at about $1200 \mathrm{~m}$, which descends abruptly from pine forest. A brief 
characterization of its plant communities can be found in the publication of Fisher-Meerow and Judd (1989), who classified the area as premontane wet forest, rich in epiphytes. Moss was sampled three times in this area, in July of 2004, late June of 2005 and mid July of 2006. Climatic conditions in 2004 and 2005 and 2006 were strikingly different. July of 2004 was relatively dry and the moss was dry as well. This year yielded no flea beetles. Late June of 2005 and July of 2006 were much wetter and moss was abundant and green. Two species of flea beetles were extracted from moss samples using a Berlese funnel. One was Aedmon sp. and another belongs to a new genus described below. One more species of that genus was found in 2006 in Sierra de Neiba, in the forest (Fig. 27) as rich in epiphytes as the forest in Las Abejas.

Beetles were retrieved from sifted moss samples by Berlese extraction. Dissecting techniques and terminology for most internal and external structures follow (Konstantinov 1998). Terminology for thoracic structures follows (Chamorro-Lacayo and Konstantinov 2004). Specimens are deposited in the collection of the National Museum of Natural History, Smithsonian Institution, Washington, D.C. (USNM) and Carnegie Museum, Pittsburg, PA (CMNH).

\section{Kiskeya new genus}

(Figs. 1-24)

Description. Body (Figs. 1-3) length $1.06-1.10 \mathrm{~mm}$, width $0.86-1.02 \mathrm{~mm}$, round, convex in lateral view (1.4 times as long as thick). Color black with light greenish or bluish luster. Femur dark brown, rest of legs and antenna dark yellow.

Head (Figs. 2, 4-7) nearly hypognathous, flat in lateral view. Frons and vertex forming nearly straight line (Figs. 6, 7) in lateral view. Supraorbital pore indistinguishable among four setae situated above eye. Antennal callus undeveloped. Midfrontal, suprafrontal, and supracallinal sulci absent. Suprantennal sulcus absent (K. baorucae) or present (K. neibae). Supraorbital and orbital sulci well developed, deep. Subgenal suture shallow along base of mandible. Orbit 0.53 times as wide as transverse diameter of eye. Interantennal space 2.37 times as wide as transverse diameter of eye and 3.45 times as wide as transverse diameter of antennal socket. Frontal ridge wide. Anterofrontal ridge not separated from frontal ridge. Eyes protruding laterally. Labrum with four setiferous pores. Apical margin concave, with short sensilla on each side. Labium with three palpomeres per palpus, two basal palpomeres wider than long. Maxillary palpus with four palpomeres, apical palpomere much smaller than preapical. Antenna with nine antennomeres, clavate.

Pronotum (Figs. 1, 4, 6, 8, 9) 2.05 times wider than long (measured in middle), without impressions. Sides weakly rounded and relatively narrowly explanate, converging gradually from base to apex. Anterolateral callosity unusually long, with anterior pore situated near basal margin and near posterior pore. Posterolateral callosity not protruding. Basal margin evenly convex, without distinct border, sloping ventrally on both sides. Anterior coxal cavity closed. Intercoxal prosternal process shaped as tall, sharp ridge widened anteriorly and posteriorly (Figs. 10, 11).

Mesoscutellum tiny and barely visible, flat, and triangular (Fig. 1). Mesocoxae separated by both meso- and metasterna. Mesosternal intercoxal process (Figs. 12, 14) with sides converging, narrowly rounded on top. Mesosternum anterior to intercoxal process with two transverse, lateral ridges forming wider 


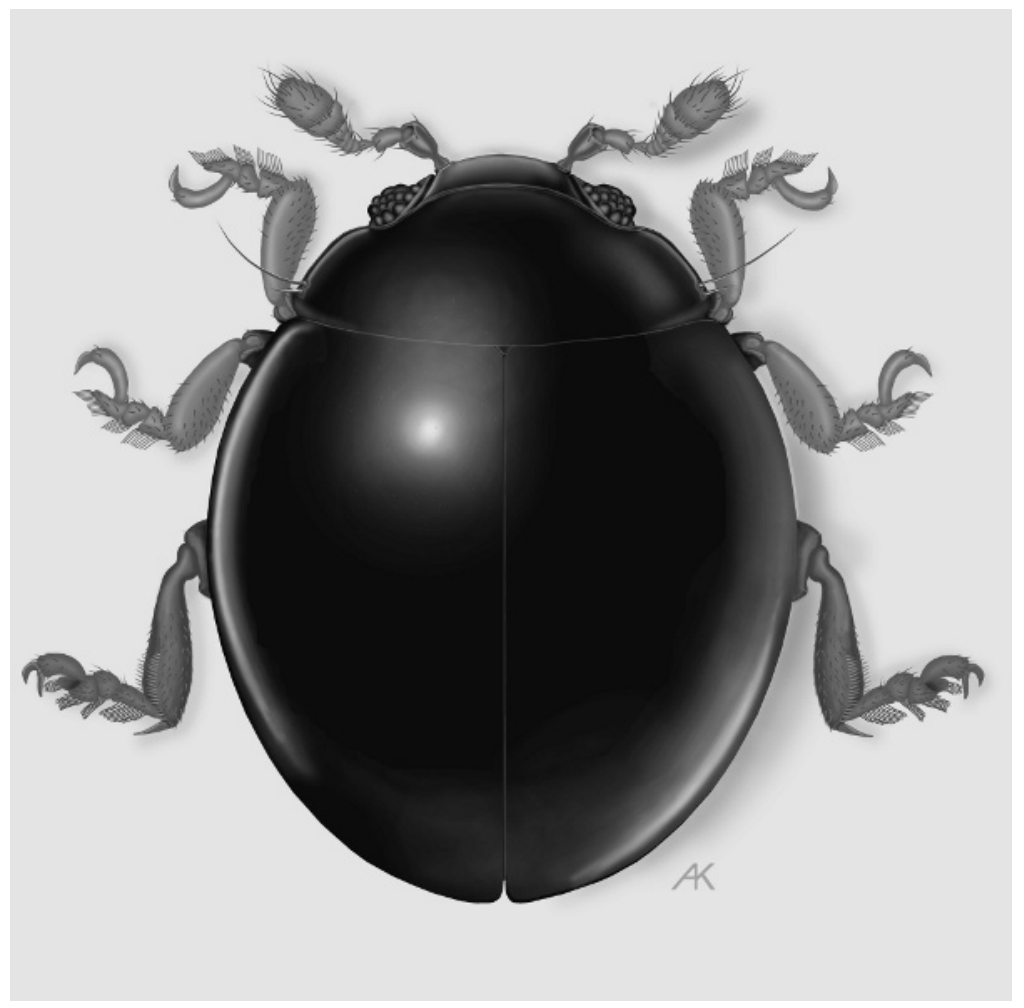

Fig. 1. Dorsal habitus of Kiskeya baorucae new species.

ridge in middle, reaching anterior margin of mesosternum. Mesepisternum much broader than mesepimeron.

Metanotum greatly simplified (Fig. 17), consisting only of sclerotized allocrista. Metasternum (Figs. 12, 14) slightly shorter than mesosternum, with deep, heart-shaped impression in middle surrounded by high ridge.

Elytron (Figs. 15, 16) with maximum width near mid-length. Humeral callus absent. Elytral apex narrowly rounded, surrounded by distinct border. Epipleura broad, nearly vertical anteriorly, reaching to sutural margin of elytron. Lateral margin of elytron continued ventrally beyond epipleura near pronotum, delimiting epipleura dorsolaterally. Elytron with sensilla spread evenly throughout surface, not grouped in patches. Hind wings absent.

Profemur slightly flattened dorsoventrally, 2.64 times as long as wide. Mesofemur flat dorsoventrally, 1.71 times as long as wide. Metafemur robust, flat dorsoventrally, with large hump on anterolateral margin (Fig. 12), 1.58 times as long as wide. Pro- and mesotibiae round in cross section, without apical spine. Metatibia (Fig. 13) slightly curved in dorsal view, straight in lateral view, flat dorsoventrally, 3.37 times as long as wide, without serration on the outer edge and without preapical excavations on both inner and outer edges; apical spur longer than tarsal claw. Claw simple (Figs. 5, 13). 


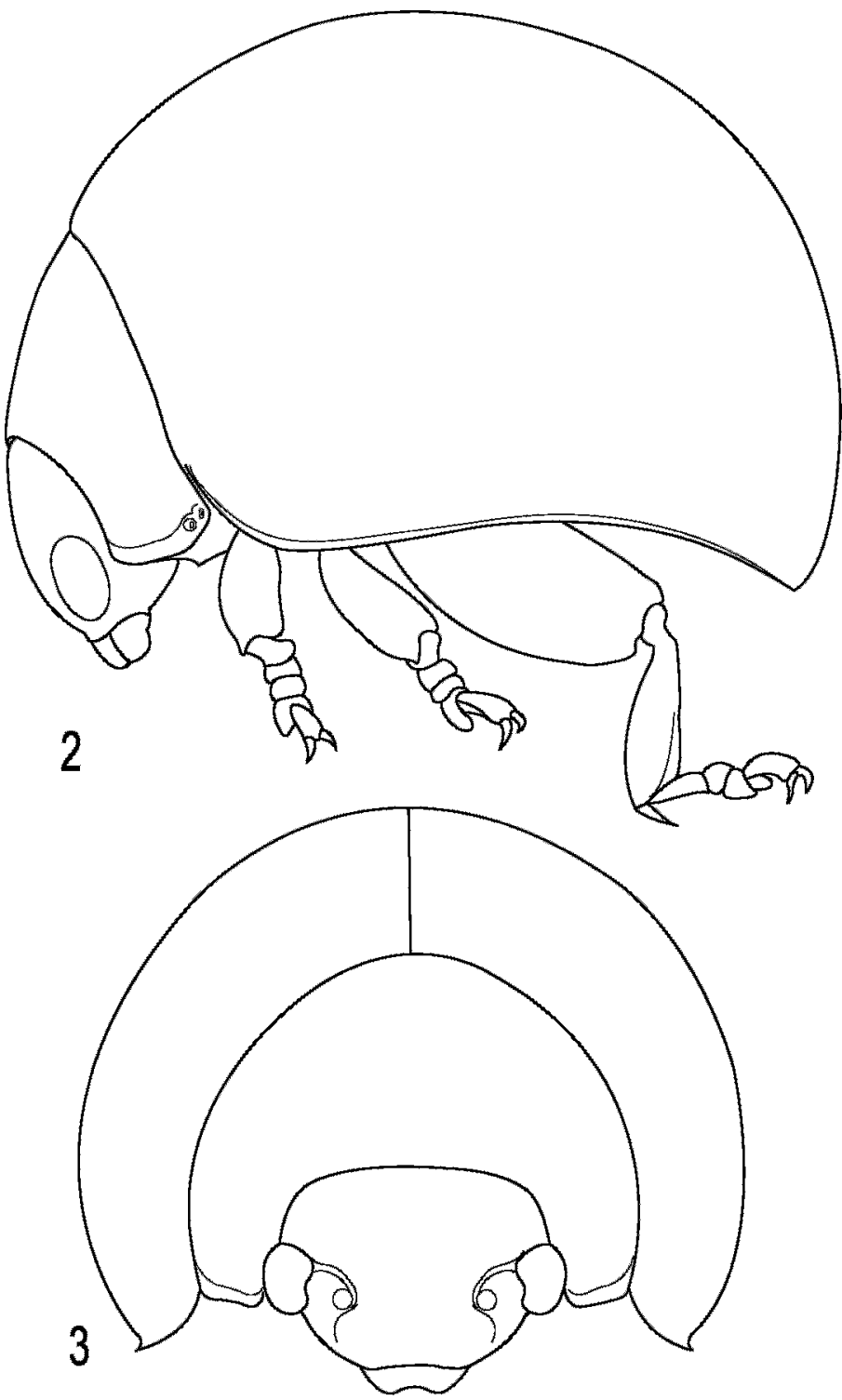

Figs. 2, 3. Kiskeya baorucae. 2) lateral view; 3) frontal view.

Abdomen with five visible distinct sternites (Figs. 12, 14). Apical sternite as long as three preceding sternites combined, without appendages basally. Basal sternite with tall and sharp longitudinal ridge. Apical tergite of female nearly triangular, unevenly covered with long setae, sclerotized posteriorly and in middle (Fig. 20). Tergite 9 strongly sclerotized posteriorly (Fig. 18). 

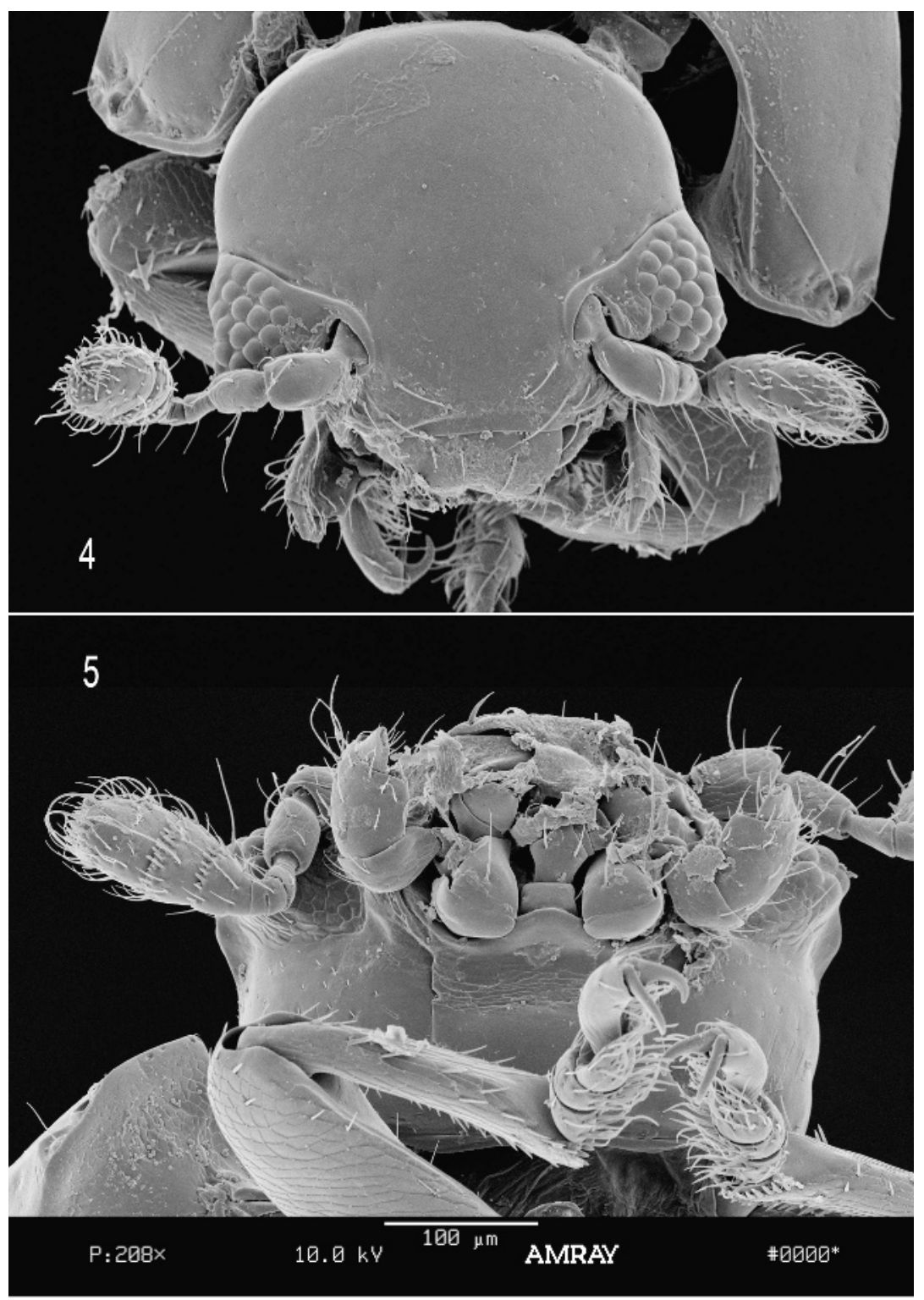

Figs. 4, 5. Kiskeya baorucae. 4) frontal view; 5) ventral view.

Spermatheca (Fig. 22) with receptacle gradually transitioning into pump without distinct border between. Basal, pre-gland part of duct absent. Tignum (Fig. 21) narrowing anteriorly, slightly wider posteriorly. Vaginal palpi (Fig. 19) slender, more widely separated anteriorly than posteriorly. 


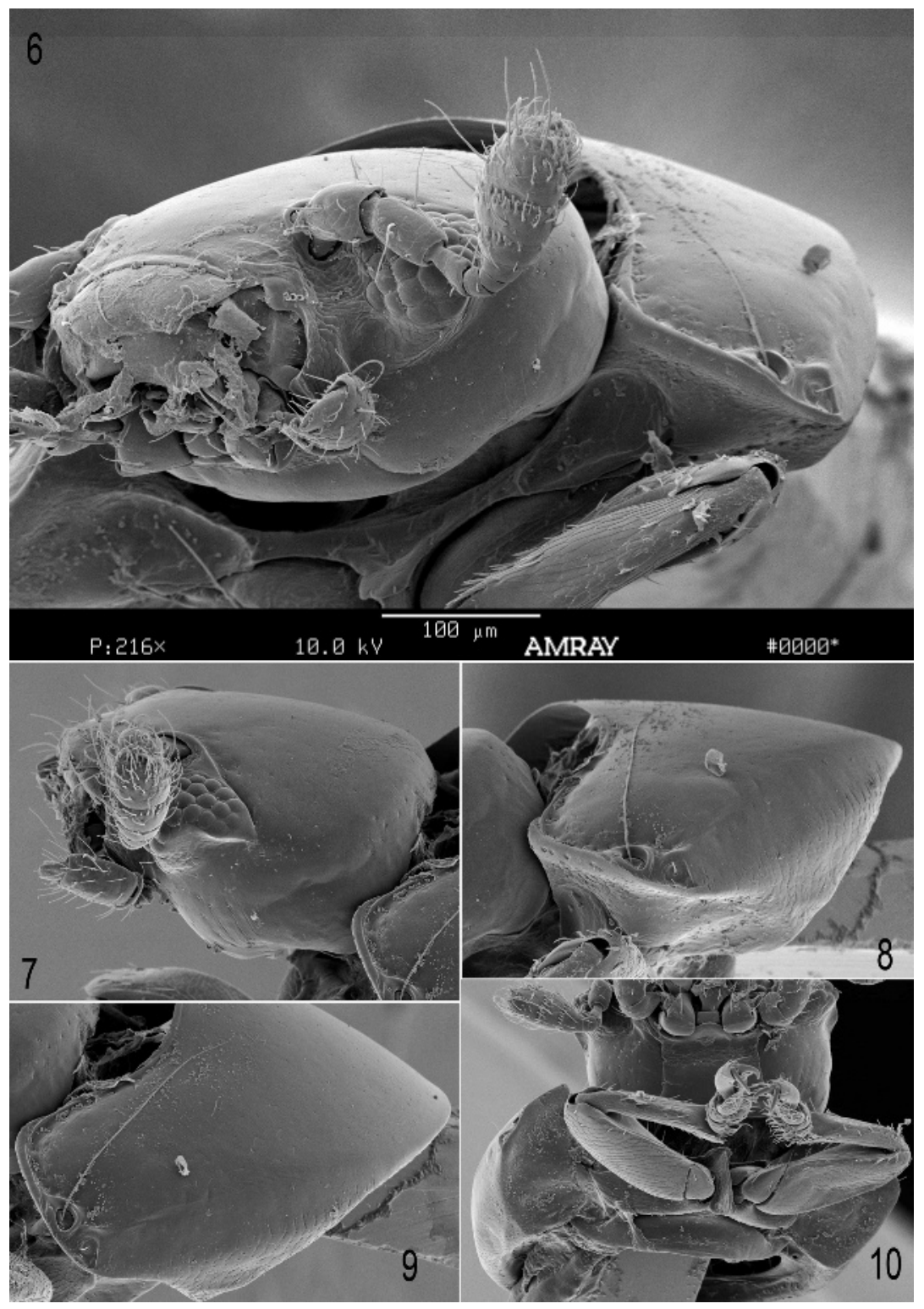

Figs. 6-10. Kiskeya baorucae. 6, 7) head (ventrolateral and lateral views); 8-10) prothorax (lateral, dorsolateral, and ventrolateral views).

Median lobe of aedeagus (Fig. 23, 24) simple, convex in lateral view, without any sculpture ventrally, without membranous window. Basal part long and flat in lateral view. 


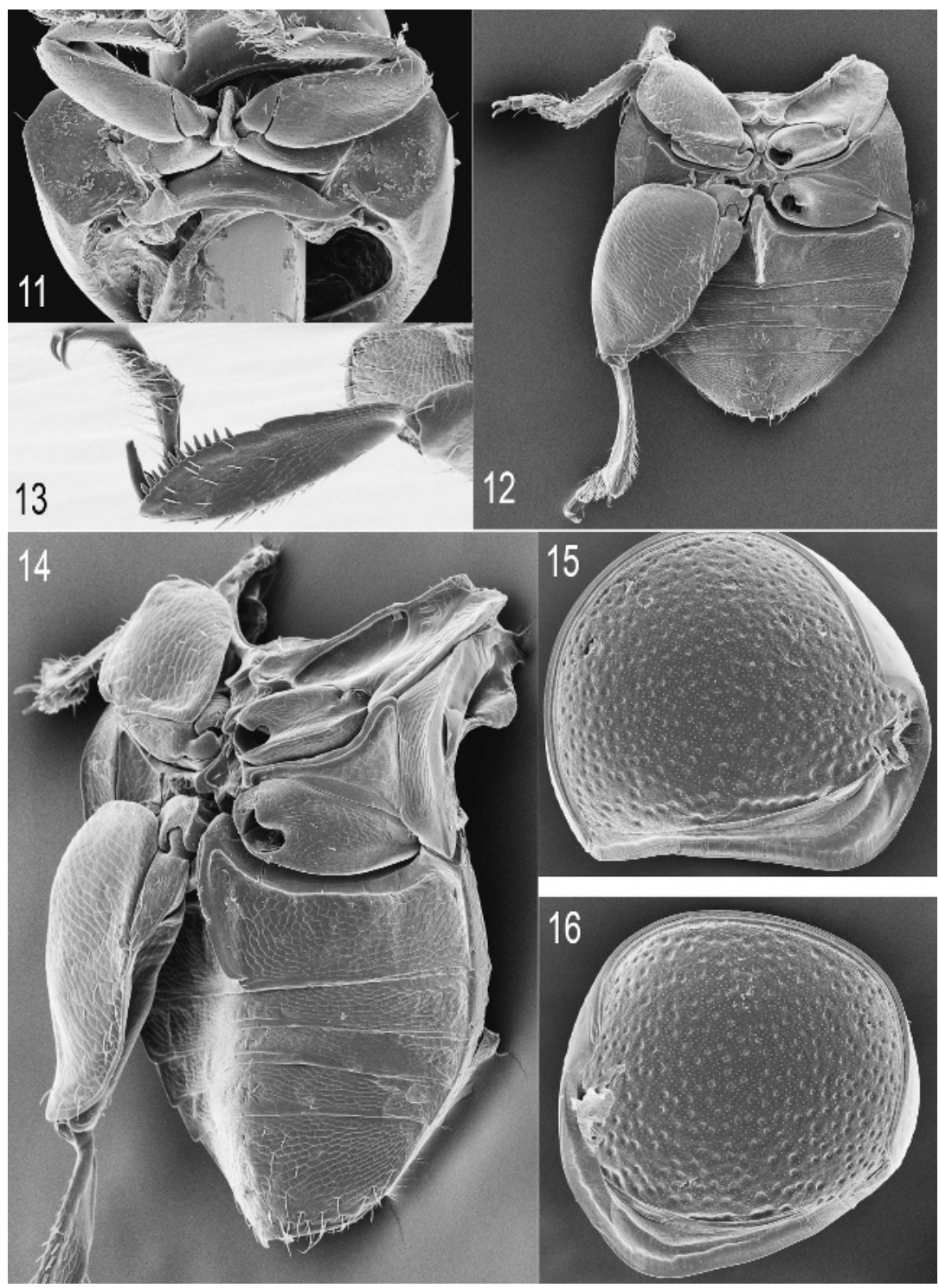

Figs. 11-16. Kiskeya baorucae. 11) prosternum; 12) body in ventral view with removed prothorax; 13) metatibia; 14) body in ventrolateral view; 15) left elytron; 16) right elytron.

Type species. Kiskeya baorucae new species

Etymology. This genus is named after the island Hispaniola which was called Kiskeya by the Arawak/Taino Indians native to the island. The name is feminine.

Diagnosis and comparison. Kiskeya can be separated from all known flea beetle genera by the following unique features: clavate antenna with only nine 

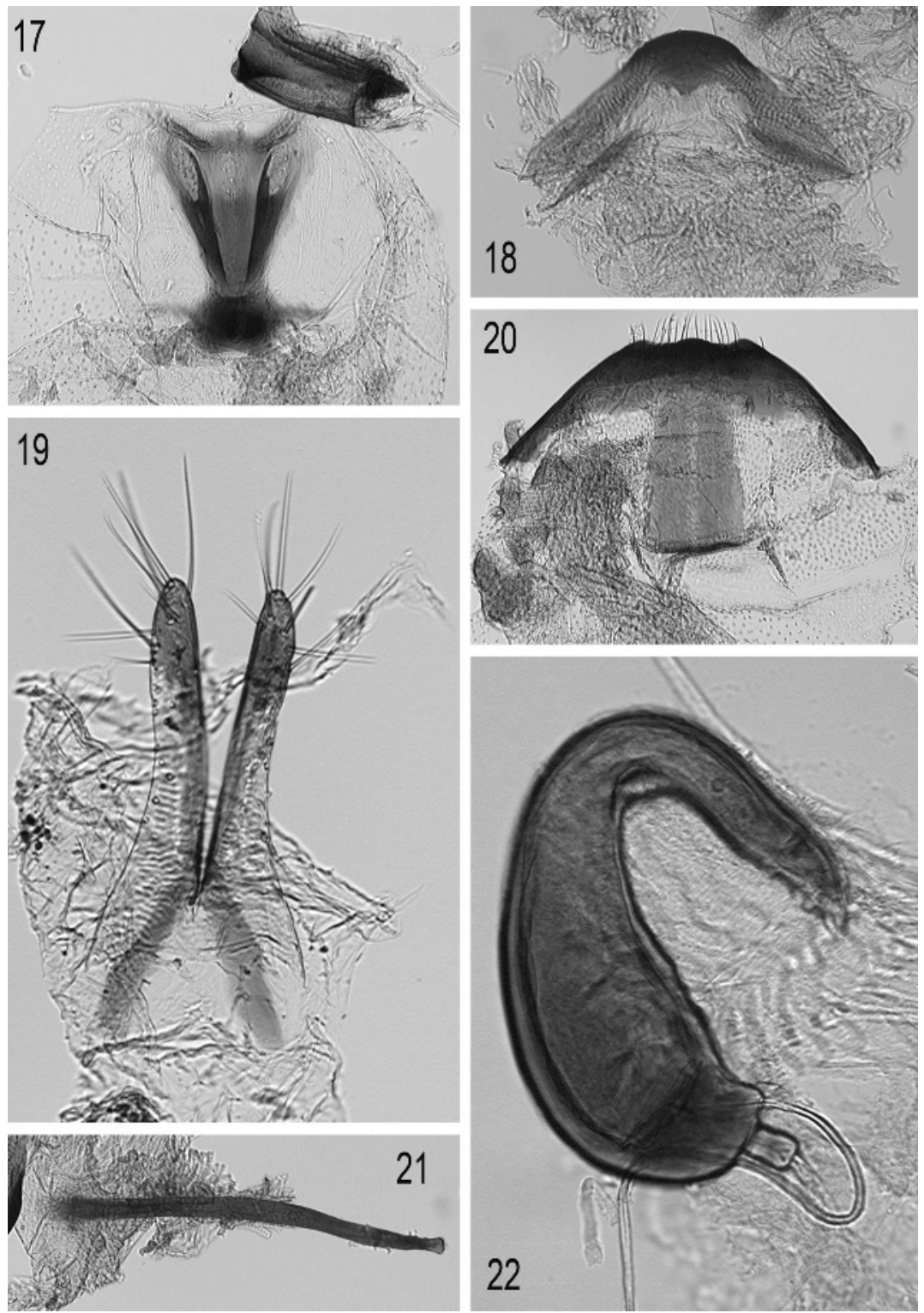

Figs. 17-22. Kiskeya baorucae. 17) meso and metaterga; 18) ninth abdominal tergite of female; 19) vaginal palpi; 20) eighth abdominal tergite of female; 21) tignum; 22) spermatheca. 

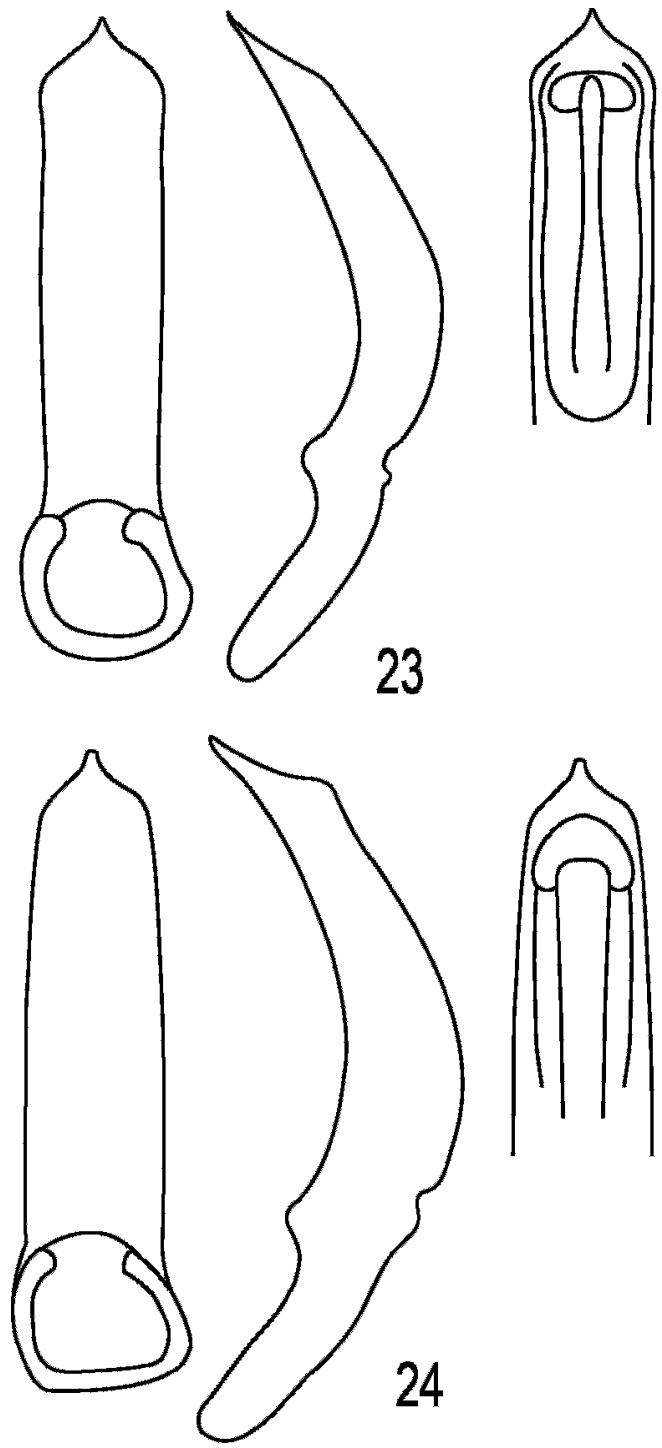

Figs. 23, 24. Median lobe of the aedeagus of Kiskeya species (ventral, lateral, and dorsal views). 23) $K$. baorucae; 24) $K$. neibae.

antennomeres; pore of anterolateral callosity of pronotum situated near basal margin adjacent to posterior pore; basal margin of pronotum without border, sloping ventrally near sides; and spermathecal duct absent basally, so the gland and the distal part of the duct arise directly on the receptacle.

Among New World flea beetles, Kiskeya is similar to Monotalla Bechyne, both genera characterized by a small, round, and wingless body, absence of the 
impression on the pronotum, and clavate antennae (Savini and Furth 2001). Apart from its unique features, Kiskeya can be separated from Monotalla based on the nine antennomeres (Monotalla has 10); absence of all sulci surrounding the antennal calli (Monotalla has antennal calli separated by the supracallinal, midfrontal, and suprafrontal sulci); the relatively short metasternum that is slightly shorter than mesosternum (it is as long as the pro- and mesosterna combined in Monotalla); and the shape of the metatibia, which is much wider, without serration on the outer edge, and without preapical excavations on both the inner and outer edges (Monotalla's metatibia has a serrated outer edge and preapical excavations on both the inner and outer edges). Kiskeya also shares clavate antennae and a round body with Normaltica Konstantinov, also known from the Greater Antilles. It can be separated easily from Normaltica based on the nine antennomeres (Normaltica has 11); absence of most head sulci (Normaltica has a full set); and completely different thoracic and genitalic structures (Konstantinov 2002).

Among Old World genera, Kiskeya is most similar to Clavicornaltica Scherer. These genera share a number of important features: clavate antennae; head lacking most sulci and both frontal and anterofrontal ridges; eyes protruding laterally beyond head limits, with a small number of relatively large ommatidia; long anterolateral callosity of pronotum which places the anterior setiferous pore close to the posterior pore; flattened meso- and metatibiae (latter with large spur); first abdominal sternite with tall longitudinal ridge; and intercoxal prosternal process shaped as tall, sharp ridge widened anteriorly and posteriorly [present in Clavicornaltica longsheng Konstantinov and Duckett, although flat in some other species (e. g., C. dali Konstantinov and Duckett)].

Kiskeya can be separated from Clavicornaltica by the following characters: antennae with 9 antennomeres (Clavicornaltica has 11): absence of suprafrontal sulcus (present in Clavicornaltica); supraorbital pore indistinguishable among four setae situated above eye (it is well developed in Clavicornaltica); apical maxillary palpomere much smaller than preapical (it is as long as preapical in Clavicornaltica); mesosternum clearly visible and not covered by metasternum as in Clavicornaltica; epipleura nearly vertical (horizontal in Clavicornaltica); basal, pre-gland part of spermathecal duct absent [in some Clavicornaltica species $(C$. tamdao Konstantinov and Duckett) the duct is very short, but is still there]; and vaginal palpi loosely attached basally and not widely separated (merged basally and widely separated in Clavicornaltica).

\section{Kiskeya baorucae new species}

(Figs. 1-23)

Description. Body length 1.06-1.10 mm, width 0.86-1.02 mm. Color black with light greenish luster. Femur dark brown, rest of legs and antenna dark yellow. Vertex smooth, without punctures or wrinkles. Supraantennal sulcus absent. Pronotum with tiny, sparse, sharp punctures. Elytron convex in lateral view [length (from apex to connection with pronotum) nearly equal to height], with tiny, sparse, barely visible punctures. Proportions of protarsomeres of female (starting with first) 9:4:6:11; mesotarsomeres 7:3:7:11; metatarsomeres 11:3:7:12. In male, proportions as follows: protarsomeres 9:4:5:10; mesotarsomeres 7:3:6:11; metatarsomeres 12:4:7:12. Apical tergite of female sinuous at apex (Fig. 20). Vaginal palpi widely separated anteriorly, with eight long setae posteriorly (Fig. 19). Posterior sclerotization straight medially, laterally curved towards middle, narrowly rounded at apex. Spermatheca (Fig. 22) with receptacle longer 

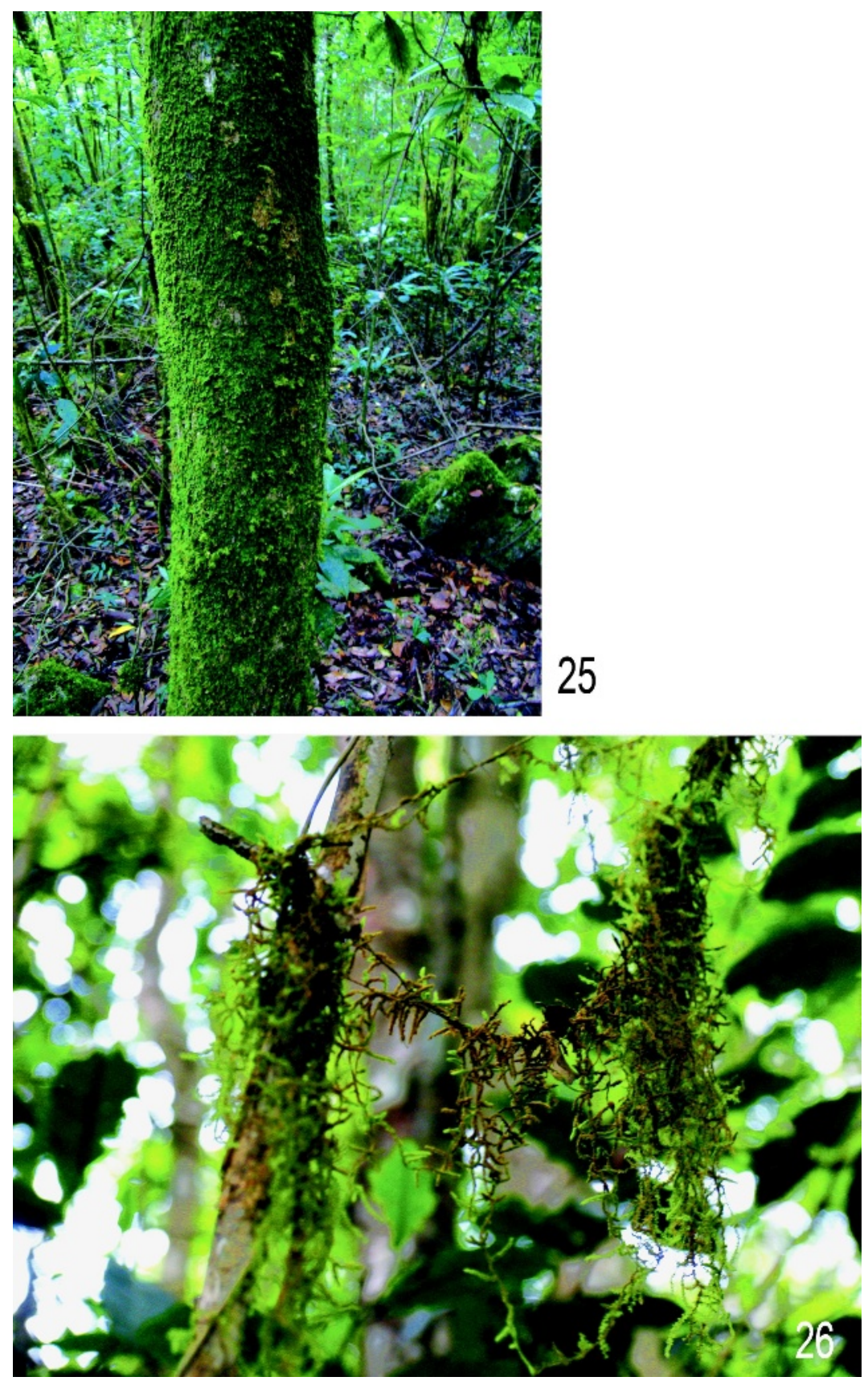

Figs. 25, 26. Habitats of Kiskeya baorucae in Sierra de Baoruco. 25) tree covered in moss; 26) moss hanging from branches. 
and wider than pump. Outer side of receptacle convex, inner side slightly concave. Vertical part of pump much shorter than horizontal. Apex of pump with small denticle. Tignum curved laterally, posterior sclerotization without sharp borders (Fig. 21). Apex of median lobe of aedeagus ogival in shape with well developed, long, and acute denticle (Fig. 23). Apex slightly curved dorsally in lateral view.

Etymology. The specific epithet is a noun in apposition based on the type locality.

Ecology. Unidentified moss samples which contained $K$. baorucae were collected in the forest from a variety of substrates (rocks, tree stumps, trunks and branches) (Figs. 25, 26) in both 2005 and 2006. Labels on specimens from Carnegie Museum indicate sweeping as a method of collecting.

Type material. Holotype male. Labels: 1) Dominican Republic: Pedernales Prov., PN Sierra de Baoruco, Las Abejas $1270 \mathrm{~m}, 18^{\circ} 09.008^{\prime} \mathrm{N}, 71^{\circ} 37.338^{\prime} \mathrm{W}$ 18.VI.2005, moss sifting, leg. A. Konstantinov \& L. Chamorro; 2) Holotype Kiskeya baorucae des. A. Konstantinov \& L. Chamorro, 2006 (USNM). Paratypes: 2 males, 4 females, same labels as holotype (USNM); 2 males, 3 females, same label as holotype except for the date 17.VII.2006; 1 male, 1) Dominican Republic: Pedernales La Abeja, 38 km NNW Cabo Rojo, 18-09N, 7138W; 2) 1250 m. 15 July 1987, John E. Rawlins and Robert L. Davidson; 3) Carnegie Museum specimen number CMNH-376.066 (CMNH); 1 male, same label as previous specimen except for the number CMNH-377.650 (CMNH); 1 female, 1) Dominican Republic: Pedernales. 3.3 km NE Los Arroyos. 18-15N, 7145W 1450 m; 2) 16-18 July 1990, L. Masner, J. Rawlins C. Yong. Wet montane forest; sweep sample; 3) Carnegie Museum Specimen Number CMNH-376.290 (CMNH); 1 male, same label as previous specimen except for the number CMNH-376.906 (USNM).

\section{Kiskeya neibae new species}

(Fig. 24)

Description. Body length 1.11-1.18 mm, width 0.88-0.94 mm. Color black with light bluish luster. Femur dark brown, rest of legs and antenna dark yellow. Vertex smooth, without punctures or wrinkles. Supraantennal sulcus present. Pronotum with tiny, sparse, sharp punctures. Elytron convex in lateral view [length (from apex to connection with pronotum) nearly equal to height], with sparse punctures slightly larger than in K. baorucae. Proportions of tarsomeres of male as follows: protarsomeres 9:5:6:11; mesotarsomeres 9:3:7:11; metatarsomeres 12:3:6:12. Female unknown. Apex of median lobe of aedeagus ogival in shape with well developed, long, and narrowly rounded denticle (Fig. 24). Apex thick and straight in lateral view.

Etymology. The specific epithet is a noun in apposition based on the type locality.

Ecology. Unidentified moss samples which contained $K$. neibae were collected in the forest (Fig. 27) from a variety of substrates (rocks, tree stumps, trunks and branches) (Fig. 28) in 2006. One broken specimen and 5 elytra were retrieved by Berlese extraction along with two male specimens.

Type material. Holotype male. Labels: 1) Dominican Republic: Elías Piña Prov., Sierra de Neiba, $1.5 \mathrm{~km}$ E of Military Post 204 (SW of Aniceto Martínez), $1597 \mathrm{~m} \mathrm{12.VII.2006} 18^{\circ} 41.644^{\prime} \mathrm{N}, 7^{\circ} 46.457^{\prime} \mathrm{W}$ leg. A.Konstantinov \& L.Chamorro; 2) Holotype Kiskeya neibae des. A. Konstantinov \& L. Chamorro, 2006 (USNM). Paratypes: 1 male, same labels as holotype (USNM). 

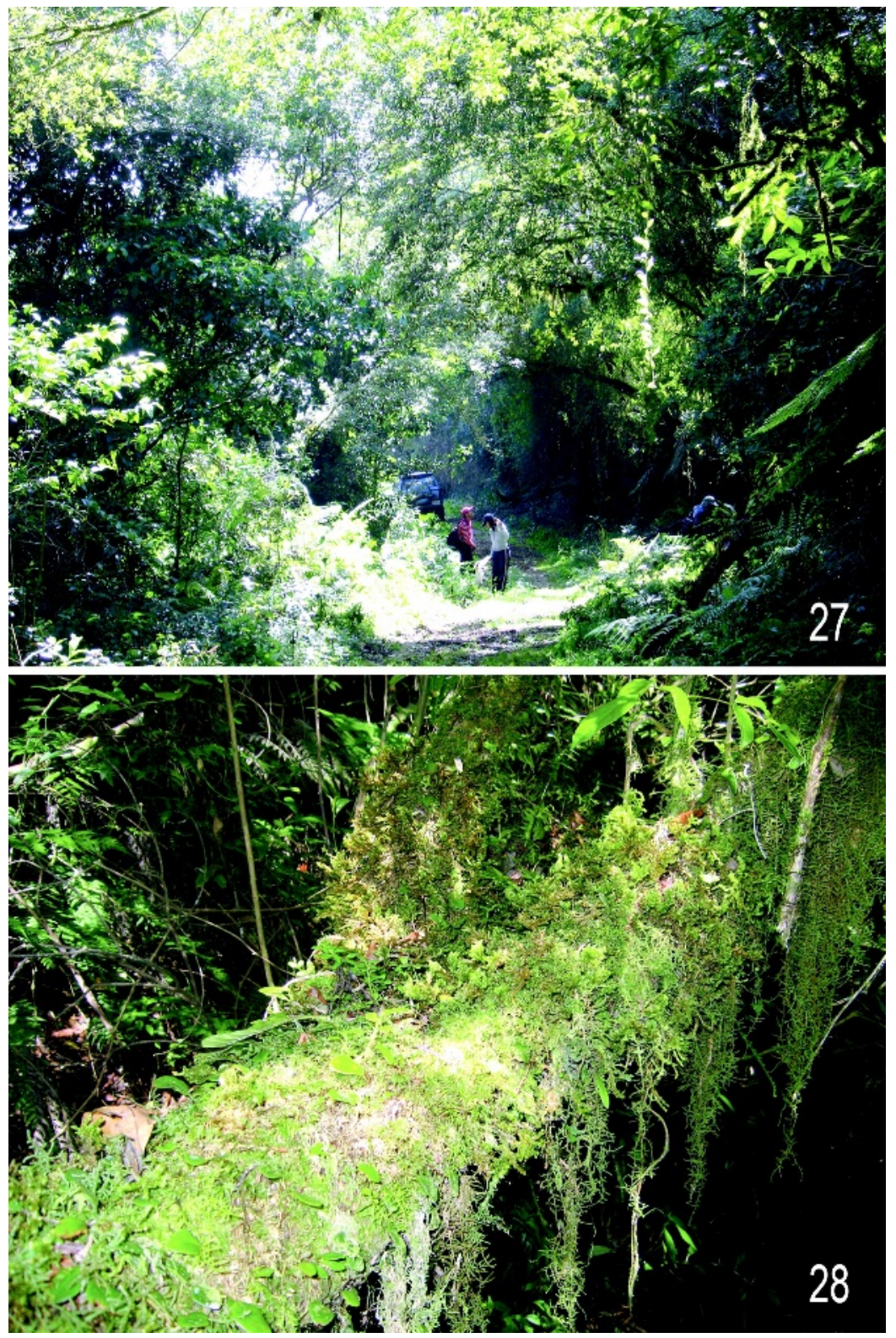

Figs. 27, 28. Habitats of Kiskeya neibae in Sierra de Neiba. 27) wet forest with mosses; 28) moss on a tree trunk. 


\section{Key to Kiskeya species}

1. Supraantennal sulcus present. Apex of median lobe of aedeagus thick and straight in lateral view with narrowly rounded denticle (Fig. 24) .... K. neibae

- Supraantennal sulcus absent. Apex of median lobe of aedeagus slightly curved dorsally in lateral view with acute denticle (Fig. 23) ..... K. baorucae

\section{Discussion}

A long list of important similarities between Kiskeya and Clavicornaltica suggests their relatively close relationship, despite the fact that some similarities can be attributed to the influence of their common environment, since both inhabit moss or leaf litter, which results in the reduction of wings, simplification of head and thoracic structures, and a generally smaller and rounder body. Clavicornaltica has been recorded from the Oriental region with one species in Australia and is exclusively an Old World genus. The hypothesis that Kiskeya and Clavicornaltica are closely related may be further tested as analyses of flea beetle generic relationships becomes available and additional material is collected from the Neotropical Region. So far, extensive leaf litter sifting carried out by Robert Anderson of the Canadian Museum of Nature in Central and South America revealed many flea beetles, but none are very similar to Kiskeya.

It is not improbable that such a relationship may exist, as other insect groups with Greater Antillean endemics have their closest relatives in the Old World. One example of this distributional pattern has been recorded for the damselfly genus Phylolestes Christiansen, known only from Hispaniola, yet belonging to the family Synlestidae otherwise distributed in southern Africa and tropical Asia (Odonata) (Flint 1978). The lygaeid species Pachygrontha singularis Slater is known only from Cuba; however, it is phylogenetically closest to several West African species (Hemiptera) (Slater 1988). The scaritine genus Antilliscaris Banninger has its closest relatives in the Afrotropical Region (Carabidae) (Nichols 1988). The drosophilid genus Mayagueza Wheeler, with one species in Puerto Rico, is phylogenetically closest to the genus Acletoxenus Frauenfeld occuring in Europe, the Middle East, northern Africa, South East Asia and nothern Australia (Diptera) (Grimaldi 1988). The two scarab genera Oniticellus Serville and Drepanocerus Kirby are represented by one species each in Hispaniola and the rest in the Afrotropical and Oriental Regions (Matthews 1966). The trichopteran genus Antillopscyhe Banks has two species in Cuba, one in Hispaniola (one extinct), and one in Puerto Rico, with its closest relative being the genus Pseudoneureclipsis Ulmer distributed throughout most of the Old World (Flint 1978). The cerambycid genus Xixuthrus Thomson (Cerambycidae) represents a similar distribution pattern, slightly complicated by taxonomic position of the species in question. Xixuthrus domingoensis Fisher was originally described from Hispaniola, while the rest of the Xixuthrus species are found on islands in the south Pacific (Yanega et al. 2004). Ivie (1985) transferred Xixuthrus domingoensis to Mecosarthron Buquet which contained three Brazilian species. This decision was based on examination of the holotype and one more specimen known at the time of publication (Ivie 1985). In the summer of 2005 about 20 specimens of $M$. domingoensis were collected in the Punta Cana area of the Dominican Republic and, according to Steve Lingafelter (personal communica- 
tion), the taxonomic placement of this species needs further study based on the newly collected material.

The restricted distributions of these Greater Antillean endemics are continually explained by extinctions of widespread ancestral lineages in the rest of the Neotropics following the final breakup of the supercontinent Gondwana during the late Mesozoic era (Matthews 1966; Flint 1978; Nichols 1988; Slater 1988; Grimaldi 1988). It is speculated that island inhabitants are somewhat protected from many problems (predators, parasites, extensive competition, etc.) that eventually lead to extinction of their continental relatives (Cox and Moore 2005). Cronk (1997) called this phenomenon "relict endemism."

The Caribbean region originated after the breakup of Pangea (mid-Jurassic) following the emergence in the eastern Pacific and subsequent easterly movement of the Caribbean plate, and formation of the volcanic proto-Antilles possibly forming a chain of islands in late Mesozoic (Hedges 1996). During the early and middle part of the Tertiary, southern Cuba and northern Hispaniola may have been connected and later separated, and northern and southern Hispaniola became a single landmass during the middle to late Tertiary (Hedges 1996). During the mid-Tertiary period the emergent land areas present where the Sierra de Baoruco, the Massif de La Salle (south-central Hispaniola) and the Cordilleras Central and Oriental (Hedges 1996) are located. Two species of Kiskeya are found in two neighboring but isolated mountain ranges: $K$. baorucae in Sierra de Baoruco and $K$. neibae in Sierra de Neiba. It is likely that additional Kiskeya species may be found in moss or leaf litter in high altitude areas of other mountain regions in the Dominican Republic (Cordilleras Central) and other Greater Antillean Islands.

\section{Acknowledgments}

We are grateful to P. J. Castillo, K. Guerrero, S. Lingafelter, C. Micheli, G. Nearns, R. Stanley, and N. Woodley for companionship and comradery during collecting trips to the Dominican Republic. We are most thankful to Jane Stanley and Theodore Kheel for their invitation to the Dominican Republic and their hospitality during our stay. We are also thanking staff of Casa de los Sueňos for their hospitality.

We thank J. Brown and A. L. Norrbom (Systematic Entomology Laboratory, ARS, USDA, Washington, D.C.), and A. K. Tishechkin (Department of Entomology, Louisiana State University, Baton Rouge, LA) for reviewing earlier versions of this manuscript and providing valuable suggestions. We are particularly grateful to S. Lingafelter and A. Tishechkin for productive discussion of the biogeographic part of the paper.

The second author undertook this project while at the University of Minnesota as Dr. Ralph W. Holzenthal's advisee, funded by NSF PEET grant number DEB0117772. She is grateful for the support and encouragement and for being allowed to participate in the collecting trips to the Dominican Republic.

\section{Literature Cited}

Chamorro-Lacayo, M. L., and A. S. Konstantinov. 2004. Morphology of the prothorax and procoxa in the New World Cryptocephalini (Coleoptera: Chrysomelidae: Crytocephalinae). Zootaxa 676:1-46.

Cox, M. L. 1997. The larva of the flea beetle, Mniophila muscorum (Koch, 1803) (Coleoptera: Chrysomelidae, Alticinae), not a leaf-miner. Entomologist's Gazette 48:275-283. 
Cox, C. B., and P. D. Moore. 2005. Biogeography: An ecological and evolutionary approach. Blackwell Publishing, 428.

Cronk, Q. C. B. 1997. Islands: stability, diversity, conservation. Biodiversity Conservation 6:477-493.

Duckett, C. N., K. D. Prathapan, and A. S. Konstantinov. Notes on identity and synonymy of Ivalia Jacoby (Coleoptera: Chrysomelidae) with description of a new species. Zootaxa (in press).

Fisher-Meerow, L. L., and W. S. Judd. 1989. A floristic study of five sites along an elevational transect in the Sierra de Baoruco, prov. Pedernales, Dominican Republic. Moscosoa 5:159-185.

Flint, O. F. Jr. 1978. Probable origins of the West Indian Trichoptera and Odonata faunas [pp. 215-223]. In: Proceedings of the 2nd International Symposium on Trichoptera (M. I. Crichton, editor). University of Reading, England, 25-29 July 1977. Dr. W Junk Publishers, The Hague.

Grimaldi, D. A. 1988. Relicts in the Drosophilidae (Diptera) [pp. 183-213] In: Zoogeography of Caribbean Insects (J. K. Liebherr, editor). Cornell University Press, Ithaca, NY.

Hedges, S. B. 1996. Historical biogeography of West Indian vertebrates. Annual Review of Ecology and Systematics 27:163-196.

Ivie, M. 1985. The generic placement of Xixuthrus domingoensis Fisher (Coleoptera: Cerambycidae: Prioninae). Pan-Pacific Entomologist 61(3):246-250.

Konstantinov, A. S. 1998. Revision of the Palearctic species of Aphthona Chevrolat and cladistic classification of the Aphthonini (Coleoptera: Chrysomelidae: Alticinae). Memoirs on Entomology, International, Associated Publishers, Gainesville. 429 pp.

Konstantinov, A. S. 2002. A new genus of flea beetles from the Greater Antilles (Coleoptera: Chrysomelidae). Zootaxa 124:1-24.

Konstantinov, A. S., and C. N. Duckett. 2005. New species of Clavicornaltica Scherer (Coleoptera: Chrysomelidae) from continental Asia. Zootaxa 1037:49-64.

Konstantinov, A. S., and A. K. Tishechkin. 2004. The first Nearctic leaf litter flea beetle (Coleoptera: Chrysomelidae) from the Great Smoky Mountains National Park. Coleopterists Bulletin 58(1):71-76.

Matthews, E. G. 1966. A taxonomic and zoogeographic survey of the Scarabaeinae of the Antilles (Coleoptera: Scarabaeidae). Memoirs of the American Entomological Society 21:133.

Nichols, S. W. 1988. Kaleidoscopic Biogeography of West Indian Scaritinae (Coleoptera: Carabidae) [pp. 71-120]. In: Zoogeography of Caribbean Insects (J. K. Liebherr, editor). Cornell University Press, Ithaca, NY.

Savini, V., and D. G. Furth. 2001. The status of Heikertingerella, Monotalla, Pseudodibolia, and Sphaeroderma (Coleoptera: Chrysomelidae: Alticinae) in the New World. Proceedings of the Entomological Society of Washington 103(4):903-912.

Slater, J. A. 1988. Zoogeography of West Indian Lygaeidae (Hemiptera) [pp. 38-60]. In: Zoogeography of Caribbean Insects (J. K. Liebherr, editor). Cornell University Press, Ithaca, NY.

Yanega, D., D. Olson, S. Shute, and Z. Komiya. 2004. The Xixuthrus species of Fiji (Coleoptera: Cerambycidae: Prioninae). Zootaxa 777:1-10.

(Received 4 February 2006; accepted 5 October 2006. Publication date 29 December 2006.) 